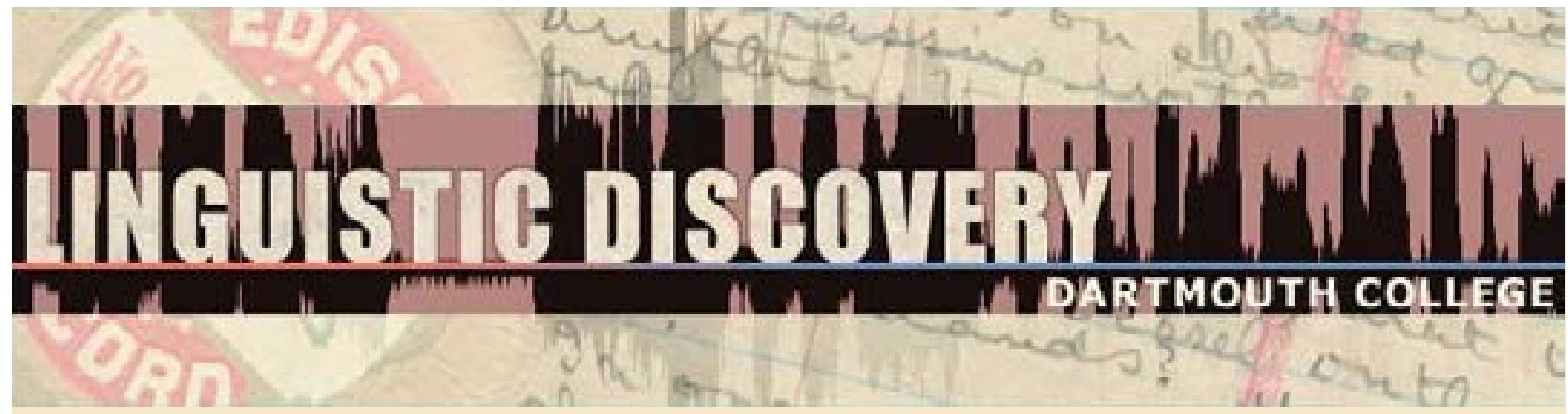

\begin{tabular}{|l|}
\hline Volume 10 \\
Issue 3 \\
2012 \\
\hline
\end{tabular}

\title{
Referential Hierarchy Effects in Yakkha Three-Argument Constructions
}

Diana Schackow

Max Planck Institute for Evolutionary Anthropology

doi: $10.1349 / P S 1.1537-0852 . A .420$

url: http://journals.dartmouth.edu/cgi-bin/WebObjects/ Journals.woa/1/xmlpage/1/article/420

\section{Linguistic Discovery}

Published by the Dartmouth College Library Copyright to this article is held by the authors. ISSN 1537-0852 linguistic-discovery.dartmouth.edu 


\title{
Referential Hierarchy Effects in Yakkha Three-Argument Constructions
}

\author{
Diana Schackow
}

Max Planck Institute for Evolutionary Anthropology

Yakkha (Kiranti language family, Nepal) has several constructions where speech act participants (SAP) and third persons are not treated alike. Such effects are found in the treatment of agents and patients of two-participant constructions, but also in the treatment of theme and goal arguments of three-participant constructions. This paper explores the referentiality effects on case marking and verbal agreement of theme and goal arguments. Crucially, most effects are scenario-based, i.e. they are conditioned not only by the properties of one argument, but by the relation between theme and goal. Besides the distinction between SAP and third person, the animacy of arguments can play a role, so that the argument realization in one construction is often conditioned by an interplay of several factors. Apart from alternations in case and agreement, Yakkha exhibits a serialization pattern that is related to an atypically high animacy of theme arguments. After analyzing these alternations and their conditions, the paper discusses how the findings match predictions that have been made about argument realization in threeparticipant constructions.

\section{Introduction}

This paper ${ }^{1}$ is a descriptive study of the effects of the referential hierarchy on the morphosyntax of three-argument verbs in Yakkha, a language of the Kiranti branch of Tibeto-Burman. The focus of this paper is on alternations in case marking, agreement and morphological changes in the verb that are triggered or restricted by the referential properties of the arguments.

Since Silverstein's (1976) seminal study on split ergativity, referential effects on alignment systems have been studied extensively. Dryer (1986) was the first to draw the attention to possible hierarchy effects in the encoding of ditransitive events, which was taken up by the typological research of Siewierska (2003), Haspelmath (2004), Haspelmath (2005), and recently by Malchukov et al. (2010). Typically, in ditransitive events the $\mathrm{G}$ argument is animate, definite and thus also more topicworthy, and the $\mathrm{T}$ argument has a strong tendency to be inanimate, indefinite and thus less topicworthy. Hence, events in which this expected scenario is reversed are more marked pragmatically and this could be reflected in the morphosyntax of the clause, for instance in special case marking for referentially low $\mathrm{G}$ arguments or high $\mathrm{T}$ arguments. This is only partly (only for $\mathrm{G}$ arguments) confirmed by the Yakkha data.

\footnotetext{
${ }^{1}$ The data and analysis presented here are part of my $\mathrm{PhD}$ research. I gratefully acknowledge the financial support of my field research by the Max Planck Institute for Evolutionary Anthropology in Leipzig (2009 and 2010) and by the German Academic Exchange Service DAAD (2011). It is due to the EUROBabel project Referential Hierarchies in Morphosyntax (RHIM) and the questionnaire on three-argument constructions designed by Anna Siewierska and Eva van Lier that I started investigating referentiality effects in three-argument verbs in Yakkha systematically. I would like to thank Eva van Lier, Françoise Rose, an anonymous reviewer and Lennart Bierkandt for their helpful comments on an earlier version. My deepest gratitude goes to the members of the the Yakkha community, without whom my research would simply not be possible: Kamala Linkha, Man Maya Jimi, Kamala Jimi, Magman Linkha, Visvakaji Kongren, Ramji Kongren, Kausila Jimi, Sonam Jimi, Indira Jimi and many others from the village of Tamaphok and from Kathmandu who took the time to work with me and provided support to my research in many ways.
} 
Another possible referentiality effect could be the alternation of the verbal agreement, i.e. the verb shows agreement with the argument that is higher on a referential hierarchy, no matter which syntactic role it has. This phenomenon, which is possible only when there is competition of arguments for one agreement slot, is known as hierarchical alignment of agreement (Nichols 1992:66). The universal tendency for agreement to be triggered by arguments that are speech act participants, animate or topical was mentioned already in Givon (1976). This principle could also hold for agreement patterns of $\mathrm{T}$ and $\mathrm{G}$ arguments of ditransitive verbs. The Yuman language Jamul Tiipay provides an example for hierarchical alignment in ditransitives (cf. Miller (2001:162-3), as discussed in Siewierska (2003:348)). Yakkha verbal agreement shows a similar behavior. Agreement (and partly also case marking) depend on the properties of both $\mathrm{T}$ and $\mathrm{G}$ argument, which constitutes hierarchical alignment in a three-participant scenario (cf. Section 2). Hierarchical effects, partly combined with inverse marking, is also known from the verbal paradigms of other Tibeto-Burman languages, e.g. from rGyalrong (Nagano 1984), Rawang (LaPolla 2007), Hayu (Michailovsky 2003) and Dumi (van Driem 1993), Hayu and Dumi being Kiranti languages as well. In Yakkha, however, it is not found in the monotransitive paradigm but only in the treatment of the $\mathrm{T}$ and $\mathrm{G}$ arguments of three-argument verbs. ${ }^{2}$

As the $\mathrm{T}$ of three-argument verbs is typically less topicworthy, salient or lower on a referential hierarchy than the $G$ argument (Haspelmath 2007), one could also expect an increase in morphological complexity in the verb when the theme is higher on the referential hierarchy or when the goal is lower than expected, i.e. "the construction which is more marked in terms of the direction of information flow should also be more marked formally" (Comrie 1989:128). Such a marking would be parallel to inverse marking for agent and patient, as found e.g. in Algonquian languages (Zuniga 2007). According to Haspelmath (2007), such verbal marking has not been found yet. Also Yakkha does not have a dedicated marker for inverse scenarios of $\mathrm{T}$ and $\mathrm{G}$. But what can be found in Yakkha is a tendency for animate or human $\mathrm{T}$ arguments to require a serial verb construction, and thus, more complexity on behalf of the verb (cf. Section 3.4).

The Yakkha data show that abundant referential effects can be found in the morphosyntax of three-participant events, even when some of these effects are not found in monotransitive verbs. Some effects are related to the referential properties of only one of the arguments, while others are conditioned by an interplay of the properties of both $\mathrm{T}$ and $\mathrm{G}$. The paper is organized as follows: The remaining parts of the first section provide an introduction into the Yakkha language and the different frames of three-argument verbs, distinguished by case and agreement. Section 2 discusses the morphosyntactic effects that are triggered by scenarios with a speech act participant $\mathrm{T}$ argument and a third person $\mathrm{G}$ argument $(\mathrm{T}[\mathrm{SAP}] \rightarrow \mathrm{G}[3])$. Case and agreement alternations and lexical distinctions related to the animacy of the $\mathrm{T}$ and $\mathrm{G}$ arguments of threeargument verbs are discussed in Section 3. Section 4 draws the threads together and summarizes the hierarchies that are relevant for the coding of three-participant events in Yakkha, as well as the different effects found in morphosyntax.

\footnotetext{
${ }^{2}$ The labels S, A, P, T, G are used for generalized semantic roles, as proposed in Dowty (1991), Bickel (2010), Witzlack (2010). They are motivated purely on semantic grounds and not by their participation in any formal construction. S stands for the sole argument of an intransitive clause, A and P stand for the most agent-like and the most patient-like argument of transitive clauses, $\mathrm{T}$ and $\mathrm{G}$ stand for the most theme-like and the most goal-like argument in ditransitive clauses.
} 


\subsection{The Yakkha language}

Yakkha belongs to the Kiranti language family. It is spoken in East Nepal, in the Sankhuwasawa and Dhankuta districts, to the East of the river Arun. The data presented in this paper were collected partly in Kathmandu, but mostly in the village Tamaphok, which is located near the Sankhuwasawa-Dhankuta border. According to the last Nepali census, there are still 14,000 speakers out of a population of roughly 17,000 ethnic Yakkha (Toba 2005), but actual numbers are likely to be smaller, and the overwhelming majority of the younger generation no longer acquires the language. Within Kiranti, Yakkha belongs to the Southeastern subbranch (also known as 'Greater Yakkha'), sharing innovations such as the aspiration of preglottalized protoinitials with other languages like Chintang and Belhare (Bickel et al. 2010).

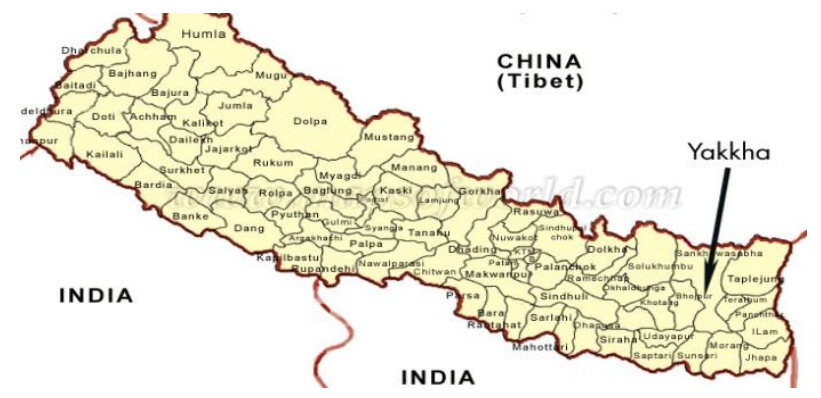

Figure 1: Map of Nepal (www.mapsofworld.com)

Kiranti languages are highly synthetic, and Yakkha is no exception to this. The verbal morphology includes agreement with both agent and patient, so that there are two separate paradigms for intransitive and transitive agreement. Negation, tense, aspect and mood are also expressed by inflectional morphology. Several morphophonological processes are at work, especially in the verbal domain, such as voicing, epenthesis and several assimilation processes. Syllable-final stops are often reduced to a glottal stop. The Yakkha person/number agreement is very complex, distinguishing singular, dual and plural number and inclusive/exclusive in the first person. In the patient agreement morphology the dual is not distinguished as consistently as in the agreement with the agent. Yakkha is overwhelmingly suffixing; there is only one prefix slot (1). This example also illustrates a further morphophonological process in Yakkha (and Kiranti languages in general) known as 'suffix copying' or 'copying of nasals' (Bickel 2003:550). Nasal suffixes can appear upto three times in one suffix string, apparently due to a preference for closing non-final open syllables with nasals. Also post-nasal voicing of stops is shown by (1), as the underlying verb stem of 'give' is /pir/.

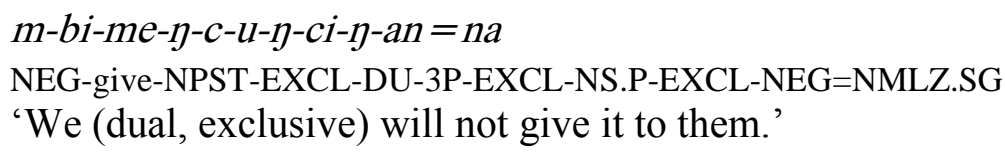

Some agreement markers show individual alignment patterns. For instance, first and second person plural have a suffix $-m$ for agreement with A arguments, but $-i$ for $S / P$ arguments (ergative alignment). Third person singular agreement is zero for $\mathrm{S}$ and $\mathrm{A}$ arguments, and $-u$ for $\mathrm{P}$ arguments (accusative alignment). The second person in turn is represented by suffix $-k a \sim-g a$ $\sim-g$, which is neutrally aligned. First person acting on second person is represented by the 
portmanteau-morpheme -nen. Some markers are underspecified $(-k a \sim-g a \sim-g$ for second person, $-m$ for speech act participant plural agents), others are ambiguous (-ci for nonsingular and for dual). Although the single markers cannot be identified straightforwardly, their meaning becomes clear from the oppositions in the paradigm, provided in Table 1 and 2 for an overview.

\begin{tabular}{|l|l|l|l|}
\hline & SG & DU & PL \\
\hline $1 \mathrm{EXCL}$ & $-\eta=n a$ & $-\eta-c i-\eta=h a$ & $-i-\eta=h a$ \\
\hline $1 \mathrm{INCL}$ & & $-c i=h a$ & $-i=h a$ \\
\hline 2 & $-k a=n a$ & $-c i-k a=h a$ & $-i-k a=h a$ \\
\hline 3 & $=n a$ & $-c i=h a$ & $N-=h a-c i$ \\
\hline
\end{tabular}

Table 1: Intransitive person and number agreement

\begin{tabular}{|c|c|c|c|c|c|c|c|}
\hline & $1 \mathrm{SG}$ & $1 \mathrm{NSG}$ & $2 S G$ & $2 \mathrm{DU}$ & $2 \mathrm{PL}$ & $3 \mathrm{SG}$ & $3 \mathrm{NSG}$ \\
\hline $1 \mathrm{SG}$ & & & $-n e n=n a$ & -nen-cin $=h a$ & \multirow[t]{2}{*}{-nen-in=ha } & $-u-\eta=n a$ & $-u-\eta-c i-\eta=h a$ \\
\hline 1DU.EXCL & & & \multicolumn{2}{|l|}{$-n e n-\operatorname{cin}=h a$} & & $-u-\eta-c-u-\eta=n a$ & $-u-\eta-c-u-\eta-c i-\eta=h a$ \\
\hline 1PL.EXCL & & & \multicolumn{3}{|l|}{-nen-in=ha } & $-u-m-\eta a=n a$ & $-u-m-c i-m-\eta=h a$ \\
\hline 1DU.INCL & & & & & & $-u-c-u=n a$ & $-u-c-u-c i=h a$ \\
\hline 1PL.INCL & & & & & & $-u-m=n a$ & $-u-m-c i-m=h a$ \\
\hline $2 \mathrm{SG}$ & $-\eta-g a=n a$ & \multirow[t]{3}{*}{$-g(a)=h a$} & & & & $-u-g a=n a$ & $-u-c i-g(a)=h a$ \\
\hline $2 \mathrm{DU}$ & \multirow[t]{2}{*}{$-g(a)=h a$} & & & & & $-u-c-u-g a=n a$ & $-u-c-u-c i-g(a)=h a$ \\
\hline $2 \mathrm{PL}$ & & & & & & $-u-m-g a=n a$ & $-u-m-c i-m-g(a)=h a$ \\
\hline $3 \mathrm{SG}$ & $-\eta=n a$ & \multirow[t]{3}{*}{$=h a$} & $-g a=n a$ & \multirow[t]{3}{*}{$-c i-g(a)=h a$} & \multirow[t]{3}{*}{$-i-g(a)=h a$} & $-u=n a$ & $-u-c i=h a$ \\
\hline $3 \mathrm{DU}$ & \multirow[t]{2}{*}{$=h a$} & & \multirow[t]{2}{*}{$N--g a=n a$} & & & $-u-c-u=n a$ & $-u-c-u-c i=h a$ \\
\hline 3PL & & & & & & $N--u=n a$ & $N--u-c i=h a$ \\
\hline
\end{tabular}

Table 2: Transitive person and number agreement

As for case marking, $\mathrm{S}$ arguments and $\mathrm{P}$ in monotransitive frames are in the unmarked nominative case (cf. Section 1.2 for the three-argument frames). The A argument is in the unmarked nominative if it is a speech act participant, and if it is a third person, it is marked with the ergative $=\eta a$, which is homophonous with the instrumental. The locative $=p e \sim=b e$ marks locations and goals in three-argument verbs. The ablative =bhay and the comitative =nuy, besides their main function of marking sources (ablative) and conjoined nouns (comitative) are also used to mark goals/sources in some verbs, and stimuli in experiencer verbs. The genitive $=k a \sim=g a$ marks dependents in possessive phrases and nouns in modifying position that denote a material (3b). An overview of the case markers can be found in Table 3, and an example is provided in (2). The constituent order is predominantly head-final (3) and SOV in affirmative and all other moods (4). The preverbal position often hosts the element in focus (4a). Word order is not syntactically constrained; it can be manipulated for purposes of information structure. As arguments are easily dropped, clauses that express all arguments overtly are rare in natural speech, even more so with three-argument verbs. ${ }^{3}$

\footnotetext{
${ }^{3}$ For that reason most example sentences used in this analysis are from elicitations. Examples that include a source
} following the translation are from narrations and conversations; the other examples are elicited. 


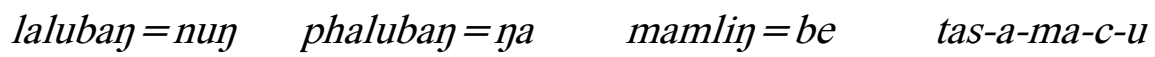

a.person=COM a.person=ERG a.village $=\mathrm{LOC} \quad$ arrive-PST-PRF-DU-3P

'Lalubang and Phalubang have arrived in Mamling.' [22_kth_05.036]

(3a)

nna $\quad$ o-hop $\quad$ wa-ya $=$ na $\quad$ sin

that 3SG.POSS-nest be-PST[3SG]=NMLZ.SG tree

'that tree where his nest was' [21_kth_04.020]

(3b) eko kolenlup $=$ ga cuplumphi

one marble $=$ GEN stele

'one marble stele' [18_kth_03.001]

anin-ga ten imin et-u-ga $=n a ?$

1PL.EXCL.POSS=GEN village how perceive-3P-2=NMLZ.SG

'How do you like our village?'

(4b) na perco?wa=na ghak et-i-si-ci-ni

this lightning=ERG all[NOM] strike-COMPL-kill-3NSG.P-OPT

'This lightning should strike and kill them all.' [21_kth_04.014]

\begin{tabular}{|l|l|}
\hline CASE & MARKER \\
\hline nominative & - \\
\hline ergative/instrumental & $=\eta j a$ \\
\hline genitive & $=k a \sim=g a$ \\
\hline locative & $=p e \sim=b e$ \\
\hline ablative & $=b h a \eta$ \\
\hline comitative & $=$ nuy \\
\hline
\end{tabular}

Table 3: Yakkha case markers

Yakkha has a nominalizing clitic that has two forms =na for singular and =ha =ya for nonsingular. This nominalizer not only derives nouns; it also marks relative clauses (shown by (3a) above) and complement clauses. Furthermore, it is frequently, but not obligatorily, attached to the verb in independent main clauses, and thus becomes interesting for the alignment of agreement markers. ${ }^{4}$ The alignment of $=n a$ (NMLZ.SG) and $=h a \sim=y a$ (NMLZ.NSG) depends on the construction: in relativizing function, the nominalizer shows agreement with the head noun, while at the end of independent clauses it mostly agrees with the number of $\mathrm{S} / \mathrm{P}$, being

\footnotetext{
${ }^{4}$ Nominalized main clauses are tentatively analyzed as focus constructions, which would fit well into the broader picture of Tibeto-Burman nominalization functions (Bickel 1999, DeLancey 2011).
} 
aligned ergatively (5). ${ }^{5}$ As the nominalizer aligns with the patient argument in transitive clauses, a study on alignment in three-argument verbs has to examine its behavior as well.

$$
\begin{aligned}
& \text { khy-a =na } \\
& \text { go-PST[3s]=NMLZ.SG } \\
& \text { 'He went.' }
\end{aligned}
$$

$$
\begin{aligned}
& \text { khy-a-ci=ha } \\
& \text { go-PST-DU=NMLZ.NSG } \\
& \text { 'They (dual) went.' }
\end{aligned}
$$

kheps-u- $\eta=n a$

hear-3P[PST]-1SG=NMLZ.SG

'I heard it/ him/ her.'

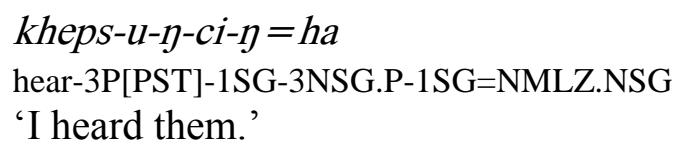

\subsection{Case and agreement properties of three-argument verbs}

For this survey not only the 'classical' ditransitive verbs, i.e. those with a recipient argument and a theme argument (Malchukov et al. 2010), were included, but all verbs referring to events that imply three participants conceptually, regardless of their specific semantic or formal properties. The reader will find among the examples verbs with locational G arguments (e.g. yuyma 'put') and verbs with instrumental $\mathrm{T}$ arguments (lupma 'cover, strew'). The reason for this decision was that restricting a survey with open results merely to a subset of potentially interesting items had the risk of missing important information that helps to understand the whole picture (cf. Margetts et al. 2007:394ff for the same argument with regard to the study of crosslinguistic variation in three-participant events). And indeed, referential effects on the morphosyntax are not only found in 'give'-type verbs. Furthermore, several verbs can occur with sentient recipient arguments as well as with locations (e.g. lepma 'throw', hambipma 'distribute'), so that the restriction to ditransitive verbs is not motivated by the semantics of three-participant events in Yakkha. The current method is based on generalized semantic roles, assigning the role 'theme' (T) to the most theme-like argument, i.e. the one that is transferred, and the role 'goal' $(\mathrm{G})$ to the most goal-like argument, i.e. the one that the event is directed to (cf. Bickel et al. (2010) for the same method in Chintang, a closely related language). The argument status of oblique-marked participants is supported also by the possibility of alternations between canonically and oblique marked frames without any derivation process and without change in the verbal semantics.

Yakkha has three different frames for three-argument verbs, distinguished by the case and agreement properties of the non-agent arguments ( $\mathrm{G}$ and $\mathrm{T})$. Several verbs can alternate between frames, or they may have some flexibility in their case marking, which will be treated in Sections 2 and 3. The A argument is always marked as in monotransitive clauses; the $\mathrm{T}$ and $\mathrm{G}$ arguments however show the following marking and indexing properties:

\footnotetext{
${ }^{5}$ The exceptions are $1>2$ scenarios and those with a first person patient, cf. paradigms in Table 1 and 2.
} 
THE INDIRECTIVE FRAME: AGR[T], T-NOM; G-LOC/ABL/COM

Verbs of the indirective frame are typically verbs of caused motion, like khupma 'bring', hayma 'send' and yuyma 'put' (6). The T argument is in the nominative case and triggers object agreement in the verb, including the choice of the nominalizer. The G argument is usually marked by a locative, with some exceptions, e.g. khuma 'steal' taking an ablative case, and incama 'sell' taking a comitative. Since the T argument is treated in the same way as patients of monotransitive verbs, the aligment is indirective in this frame.

$\begin{array}{llrl}k a & a-c y a-c i & i s k u l=b e & p a k s-w a-\eta-c i-\eta=h a \\ \text { 1SG[NOM] } & \text { 1SG.POSS-child[NOM]-NSG } & \text { school=LOC } & \text { send-NPST-1SG-3NSG.P-1SG=NMLZ.NSG }\end{array}$
'I send my children to school.'
akka
khorek cula $=g a \quad u$-yum $=b e$
yuks-uks-u- $\eta=n a$
1SG.POSS bowl[NOM] hearth=GEN 3SG.POSS-side=LOC
put-PRF-3P[PST]-1SG=NMLZ.SG
'I have put my bowl close to the hearth.'

\section{THE DOUBLE OBJECT FRAME: NMLZ[T], T-NOM; AGR[G], G-NOM}

Verbs of the double object frame often denote events of caused possession and benefactive events. Also verbs derived by the benefactive applicative occur in this frame. Although the case marking is neutral (nominative for both $\mathrm{T}$ and $\mathrm{G}$ ), the agreement is aligned secundatively, i.e. the $\mathrm{G}$ argument triggers agreement in the verb. The choice of the verb-final nominalizer, however, is slightly more complicated. In the majority of scenarios, the choice of the nominalizer is conditioned by the number of the $\mathrm{T}$ argument, so that all three arguments are indexed on the verb in this frame (compare (7a) and (7b)).

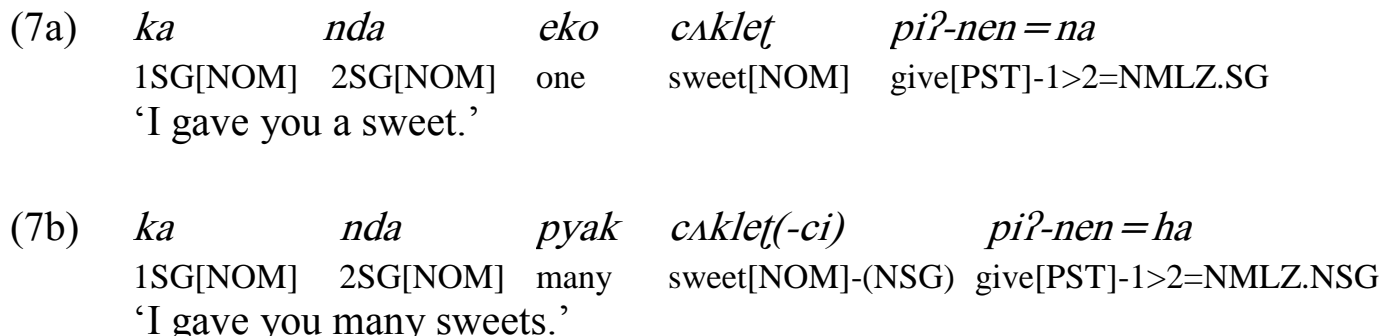

\section{THE SECUNDATIVE FRAME: T-INS; AGR[G], G-NOM}

Verbs of the secundative frame often denote events of creative or destructive impact, and the semantic role of the $T$ argument is often, but not necessarily, an instrument. In these verbs, the $G$ argument is in the nominative case and triggers verbal agreement, including the choice of the nominalizer, while the $\mathrm{T}$ argument is in the instrumental case, illustrated by (8). As the $\mathrm{G}$ argument is treated like the patient of monotransitive verbs, verbs of this frame are aligned secundatively with regard to both case and agreement. 

yapmi $=\eta \mathrm{a}$
hammana $=\eta a$
picha
$e p t-u=n a$
person=ERG blanket=INS child[NOM]
cover[3SG.A]-3P[PST]=NMLZ.SG

'The man covered the child with a blanket.'
ijay chippa-ke?-ke?=na

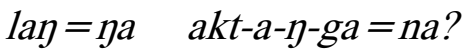
why disgust-come.up-REDUP=NMLZ.SG
foot=INS
kick-PST-1SG-2=NMLZ.SG
'Why did you kick me with (your) disgusting foot?'

Table 4 provides an overview of the three basic frames, before the alternations are discussed in the following sections. The reader should bear in mind that the terms used are just labels for the sake of readability, and particularly that the term 'double object' is motivated by the case marking properties, while the agreement and the nominalizer each prefer a different argument. In the following, I will refer to the frames by their names as they are in the table.

\begin{tabular}{|l|l|l|l|l|}
\hline Frame & Case & Agreement & NMLZ & Semantics \\
\hline Indirective & T-NOM, G -LOC & T & T & caused motion \\
\hline Double Object & T-NOM G-NOM & G & T & caused possession, benefactive \\
\hline Secundative & T-INS, G-NOM & G & G & creative or destructive impact \\
\hline \multicolumn{4}{|c|}{ Table 4: Frames of Yakkha three-argument verbs }
\end{tabular}

Three-argument verbs of all frames can be created by causative and benefactive derivation as well. In the causative derivation, the resulting three-participant frame depends on which frame the underived (monotransitive) verb had. The benefactive derivation usually leads to verbs in the double object frame. So far, the derived verbs show the same morphosyntactic properties as underived three-argument verbs concerning agreement, the alternations between classes and the possibility to undergo reflexive or reciprocal derivations.

\section{Hierarchy Effects Related to Person}

In Yakkha, one kind of scenario triggers deviations in case marking and agreement of threeargument verbs, and this is the configuration with a speech act participant $\mathrm{T}$ and a third person $\mathrm{G}$ argument (henceforth $\mathrm{T}[\mathrm{SAP}] \rightarrow \mathrm{G}[3]$ ). As not just the properties of the theme argument are important, but its properties in relation to a co-argument, this is a case of hierarchical agreement: Both $\mathrm{T}$ and $\mathrm{G}$ compete for the non-agent agreement slot, and only when $\mathrm{T}$ is higher on a SAP>3 hierarchy than $\mathrm{G}, \mathrm{T}$ triggers agreement. The effects discussed in the following are alternations in case and agreement in verbs of the double object frame (Section 2.1) and restricted alternation possibilities of the verb nakma 'ask/beg' (alternating between indirective and double object frame) (Section 2.2).

\subsection{Case and agreement alternations in double object verbs}

This section discusses alternations in the verbs sopmepma 'show' and camepma 'feed' that are triggered by the scenario $\mathrm{T}[\mathrm{SAP}] \rightarrow \mathrm{G}[3] .{ }^{6}$ Both verbs belong to the double object frame, i.e. both

\footnotetext{
${ }^{6}$ Etymologically, both verbs are causatives, but their formal properties differ from causative constructions. Causees
} 
the $\mathrm{T}$ and the $\mathrm{G}$ argument are (usually) in the unmarked nominative case, while the verb agrees with the $\mathrm{G}$ argument (secundative alignment of agreement). ${ }^{7}$ This alignment changes in scenarios with a speech act participant $\mathrm{T}$ and a third person $\mathrm{G}$ : in such configurations, the $\mathrm{T}$ argument triggers agreement in the verb, along with other changes, as described in the following.

\section{sopmepma 'show'}

Example (9) shows sentences with the standard double object frame. In (9a), the verb shows object agreement with the first person $\mathrm{G}$ argument, and the nominalizer is aligned with the third person singular $\mathrm{T}$ argument (agreement with the third person singular A argument is zero). In (9b) from a narration, the prefix stands for agreement with a plural agent, while the suffixes stand for agreement with the nonsingular $\mathrm{G}$ argument (remember that the verb-final nominalizer is optional).
$a-n a=\eta a$
$k a$
u-photo
sopmet-a- $\eta=n a$

1SG.POSS-elder.sister=ERG 1SG[NOM] 3SG.POSS-photo[NOM]

show[3SG.A]-PST-1SG=NMLZ.SG

'My elder sister showed me her photo.'

$$
\begin{array}{ll}
\text { yabenpekkhuwa-ci=ja } & n \text {-sopmet-uks-u-ci } \\
\text { shaman-NSG=ADD } & \text { 3PL.A-show-PRF-3P[PST]-3NSG.P }
\end{array}
$$

'They have also showed it to the shamans.'[22_kth_05.068]

In (10), the $\mathrm{T}$ argument is a speech act participant and the $\mathrm{G}$ argument has third person reference. Here, it is the $\mathrm{T}$ argument that triggers the agreement and determines the choice of the nominalizer. The case marking also changes, as the $\mathrm{G}$ argument has to be marked with a locative. In other words, the frame changes from double object to indirective.

$$
\begin{array}{llll}
k a & n d a & \begin{array}{l}
\text { appa-ama }=b e \\
\text { mother-father=LOC }
\end{array} & \begin{array}{l}
\text { sopme?-nen=na } \\
\text { show[PST]-1>2=NMLZ.SG }
\end{array}
\end{array}
$$

'I showed you to my parents.'

Example (11) shows a scenario where both T and G are SAPs, to demonstrate that the agreement alternation only takes place in $\mathrm{T}[\mathrm{SAP}] \rightarrow \mathrm{G}[3]$ scenarios, i.e. it is conditioned by the interplay of the properties of both non-agent arguments. The verb shows agreement with the second person plural $\mathrm{G}$ argument, although the $\mathrm{T}$ argument is a speech act participant. Case marking may change to the locative, but this alternation is optional.

$$
\begin{aligned}
& u \eta=\eta a \quad k a \quad \text { nninda }(=b e) \text { sopmet }-i-g=h a \\
& \text { 3SG=ERG } 1 \mathrm{SG}[\mathrm{NOM}] \quad \text { 2PL(=LOC) show[PST;3SG.A]-2PL-2=NMLZ.NSG } \\
& \text { 'He showed me to you (plural).' }
\end{aligned}
$$

in causative events are in the ergative case, while the $\mathrm{G}$ arguments of camepma and sopmepma do not have ergative case marking. Also conceptually, the difference between a $\mathrm{G}$ argument and a causee is clear from the situations that the utterances in the examples refer to.

${ }^{7}$ The other verbs from the double object frame do not license a SAP T argument, e.g. pipma 'give (things)', hakma 'send (things)', lupma 'tell (propositions, stories etc.)'. 
To conclude, the agreement alternation instantiates hierarchical alignment, because it is triggered by the $\mathrm{T}[\mathrm{SAP}] \rightarrow \mathrm{G}[3]$ scenario. The odds for the $\mathrm{G}$ argument to be marked with a locative are also higher when $\mathrm{T}$ is a speech act participant. ${ }^{8}$

\section{camepma 'feed'}

A slightly different pattern is exhibited by the other verb that can undergo this agreement alternation. In contrast to sopmepma 'show', camepma 'feed' never licenses a locative case; only the agreement properties change when the $T$ argument is a speech act participant and $G$ is third person. The standard frame is shown in (12). The verb agrees with the nonsingular $\mathrm{G}$ argument (third person singular $\mathrm{A}$ agreement is zero). The nonsingular nominalizer aligns with the $\mathrm{T}$ argument. 9
$u-m a=\eta a$
picha-ci
cama
camet- $u-c i=h a$
3SG.POSS-mother=ERG child-NSG[NOM]
cooked.rice
feed[3SG.A]-3P[PST]-NS.P=NMLZ.NSG
'The mother fed rice to the children.'

Example (13a) can be interpreted in two ways. If the sentence refers to a scenario of the $\mathrm{T}[\mathrm{SAP}] \rightarrow \mathrm{G}[3]$ type, the $\mathrm{T}$ argument triggers agreement in the verb; if it refers to $\mathrm{T}[3] \rightarrow \mathrm{G}[\mathrm{SAP}]$, the $\mathrm{G}$ argument triggers the agreement. The $\mathrm{G}$ argument cannot receive locative case marking, so that this alternation is not a complete alternation between the double object frame and the indirective frame. As the locative on $\mathrm{G}$ is ungrammatical, this instance of hierarchical agreement is potentially ambiguous, as it will always be the SAP argument that triggers the agreement (compare the two translations of (13a)). For disambiguation, a causative structure (distinguished only by the ergative on the causee) was proposed by the Yakkha consultants (13b). Example (13c), with both $\mathrm{T}$ and $\mathrm{G}$ being SAP, illustrates again that the agreement with $\mathrm{T}$ only applies in the scenario $\mathrm{T}[\mathrm{SAP}] \rightarrow \mathrm{G}[3] .^{10}$
ka $\quad$ nda $\quad k i b a(*=b e)$
'I will feed you to the tiger' OR
'I will feed the tiger to you!'
$1 \mathrm{SG}[\mathrm{NOM}] \quad 2 \mathrm{SG}[\mathrm{NOM}] \quad$ tiger[NOM] $(*=\mathrm{LOC})$
came?-me?-nen $=$ na
feed-NPST-1>2=NMLZ.SG
(13b)

$\begin{array}{llll}k a & n d a & k i b a=n a & c a-m e 2-m e ?-n e n=n a \\ 1 \mathrm{SG}[\mathrm{NOM}] & 2 \mathrm{SG}[\mathrm{NOM}] & \text { tiger=ERG } & \text { eat-CAUS-NPST-1>2=NMLZ.SG }\end{array}$
'I will make the tiger eat you'

\footnotetext{
${ }^{8}$ There are not enough examples available to determine the acceptability of the locative case exactly. However, in all examples that are available from elicitations and from recorded spontaneous speech the locative on $G$ is absent when $\mathrm{T}$ has third person reference.

${ }^{9}$ Mass nouns trigger the nonsingular nominalizer $=h a$. The alignment of the nominalizer is admittedly not detectable from this example, as the $\mathrm{G}$ argument has nonsingular number as well. It is clear, however from the paradigms of three-argument verbs.

${ }^{10}$ Relating to comments on an earlier draft, I would like to point out that the context for this semantically odd example could be established surprisingly easy, imagining man-eating demons and ghosts who can talk.
} 


$\begin{array}{llll}\text { un }=\eta \mathrm{l} a & \mathrm{ka} & n d a & \text { camet-a-ga=na } \\ \text { 3SG=ERG } & \text { 1SG[NOM] } & \text { 2SG[NOM] } & \text { feed[3A]-PST-2SG=NMLZ.SG } \\ \text { 'She fed me to you.' } & & \end{array}$

To summarize, the alternation between agreement with $\mathrm{G}$ and agreement with $\mathrm{T}$ is conditioned by an SAP T argument combined with a third person $\mathrm{G}$ argument. Table 5 illustrates this pattern. In sopmepma 'show', the case marking of the participants also changes, as the $G$ argument receives a locative case, so that the resulting structure belongs to the indirective frame. For camepma 'feed', the locative on $\mathrm{G}$ is ungrammatical.

\begin{tabular}{|l|l|l|}
\hline T[SAP & G[SAP] & G[3] \\
\cline { 1 - 1 } & $\begin{array}{l}\text { (G-LOC/NOM) } \\
\text { agr[T], T-NOM; G-NOM (camepma) }\end{array}$ & agr[T],T-NOM; G-LOC (sopmepma) \\
\cline { 1 - 1 } T[3] & agr[G],G-NOM; T-NOM \\
\hline \multicolumn{2}{|c|}{ Table 5: Hierarchy effects on agreement and case in double object verbs }
\end{tabular}

As person agreement favours speech act participants (and generally, human referents), the Yakkha findings are in line with the crosslinguistic observations (Siewierska 2003:356). Another potential candidate for this alternation is pipma 'give', but this verb additionally requires a serialization when human $\mathrm{T}$ arguments are involved. This animacy-driven serialization will be the topic of Section 3.4.

\subsection{Restricted alternation}

The verb nakma (stem: nakt $\sim$ nak $\sim$ nay) 'ask, beg' alternates between the indirective and the double object frame, as exemplified by (14) and (15), respectively. From the data available so far, both frames occur equally frequent in natural speech. The choice of the frame apparently has to do with which argument is more central to the event in a given context ( $\mathrm{G}$ in the double object frame, $\mathrm{T}$ in the indirective frame). Example (14a) illustrates the indirective frame: The $\mathrm{T}$ argument triggers object agreement, while the $\mathrm{G}$ argument is in the locative case. (14b) and (14c) provide additional examples from spontaneous speech. The $\mathrm{G}$ argument is rarely overt, but it is still clear from the context that the verb agrees with $T$, because $G$ is first person nonsingular in (14b) and third person nonsingular in (14c), and if the verb agreed with $\mathrm{G}$, the person inflection would look different.

$$
\begin{array}{llll}
u \eta=\eta \mathrm{a} & \mathrm{ka} a \mathrm{be} & u \text {-nipma } & \text { nakt- } u=h a \\
\text { 3SG=ERG } & \text { 1SG=LOC } & \text { 3SG.POSS-money } & \text { ask[3SG.A]-3P.PST=NMLZ.NSG }
\end{array}
$$

'He asked me for his money.'

$$
\begin{array}{ll}
i=y a & \text { nay-me-c- } u-g=h a ? \\
\text { what=NMLZ.NSG } & \text { ask-NPST-DU-3P-2=NMLZ.NSG }
\end{array}
$$

'What do you (dual) ask (us) for?' [22_kth_05.110]

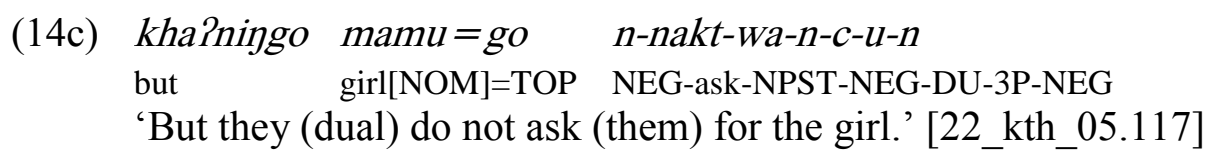


Example (15a) illustrates the double object frame: The verb agrees with the $\mathrm{G}$ argument, and both $\mathrm{T}$ and $\mathrm{G}$ are in the unmarked nominative case. (15b) and (15c) are supplementary examples from spontaneous utterances. The $\mathrm{G}$ argument is non-overt, but the verb shows agreement with $\mathrm{G}$, thus providing evidence for the double object frame. According to currently available data, the verb chooses the most topical argument to agree with, exemplified by (15d), with additional topic markers leaving no doubt about the pragmatic status of $\mathrm{T}$. The (non-overt) SAP G argument would be higher referentially, but still the verbs agrees with the more topical T, and hence follows the indirective frame.

(15a) $\mathrm{ka}$ nda chemha nak-nen $=$ ha

1SG[NOM] 2SG[NOM] liquor[NOM] ask[PST]-1>2=NMLZ.NSG

'I asked you for liquor.'

(15b) $k a$

$$
i=y a=c a \quad n-n a k t-a-\eta-a n !
$$

$1 \mathrm{SG}[\mathrm{NOM}]$ what=NMLZ.NSG=ADD NEG-ask-IMP-1SG-NEG

'Do not ask me for anything!' [27_kth_06.25]

\section{(15c) bhaka}

n-nakt-wa-ci

fixed.wedding.date[NOM] 3PL.A-ask-NPST-3NSG.P

'They will ask them to fix the wedding date.' [25_biha_01.19]

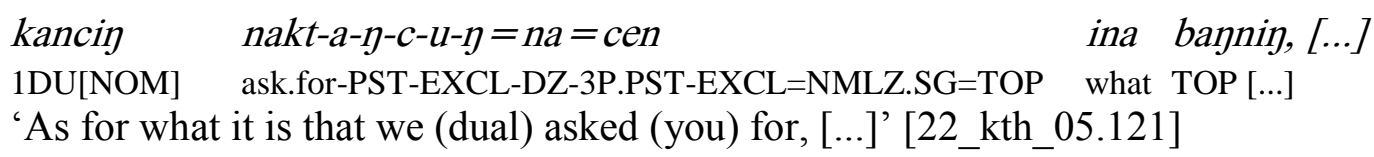

These basic conditions notwithstanding, this alternation is not unrestricted. Under the same scenario that was discussed in Section 2.1, namely $\mathrm{T}[\mathrm{SAP}] \rightarrow \mathrm{G}[3]$, the double object frame is ungrammatical, as example (16a) illustrates. If the T argument is a speech act participant, and $\mathrm{G}$ is not, the verb cannot agree with $\mathrm{G}$. The $\mathrm{T}[\mathrm{SAP}] \rightarrow \mathrm{G}[3]$ scenario permits only the indirective frame, to facilitate the agreement with $\mathrm{T}(16 \mathrm{~b})$. Example (16c) is parallel to (16a), but with a third person $\mathrm{T}$ argument. It provides evidence for the grammaticality of the double object frame when the $\mathrm{T}$ argument is not a speech act participant.

$$
\begin{array}{lll}
{ }^{*} \text { unci } & k a & n \text {-nakt-u-n-ci-n} \\
\text { 3NSG[NOM] } & \text { 1SG[NOM] } & \text { NEG-ask-3P[IMP]-NEG-ns.P-NEG }
\end{array}
$$

Intended: 'Do not ask them for me.' (*double object frame)

(16b) ka nda unci=be nak-nen =na

1SG[NOM] 2SG[NOM] 3NSG=LOC ask[PST]-1>2=NMLZ.SG

'I asked them for you.' (indirective frame)

(16c) unci $\quad i=y a=c a \quad n-n a k t-u-n-c i-n$

3NSG[NOM] what=NMLZ.NSG=ADD NEG-ask-3P[IMP]-NEG-3NSG.P-NEG

'Do not ask them for anything.' (double object frame) 
Table 6 below summarizes the restricted alternation. According to the data gathered so far, this is the only verb that may alternate between the double object and the indirective frame with the restriction in the $\mathrm{T}[\mathrm{SAP}] \rightarrow \mathrm{G}[3]$ scenario.

\begin{tabular}{|l|l|l|}
\hline & G[SAP] & G[3] \\
\hline T[SAP] & agr[T], T-NOM; G-LOC $\sim$ & agr[T],T-NOM; G-LOC \\
\hline T[3] & agr[G], G-NOM/LOC; T- & \\
& NOM & \\
\hline
\end{tabular}

Table 6: Restricted alternations in nakma 'ask'

This section showed how an atypical configuration of the referential properties of $\mathrm{T}$ and $\mathrm{G}$ has effects on the coding of non-agent arguments of three-argument verbs in Yakkha. The first effect that was described was an agreement alternation (and partially also alternation in case) conditioned by a first or second person $\mathrm{T}$ argument and a third person $\mathrm{G}$ argument. The second effect was a restriction in alternation possibilities that was conditioned again by the atypical scenario $\mathrm{T}[\mathrm{SAP}] \rightarrow \mathrm{G}[3]$.

\section{Alternations Related to the Animacy of the Arguments}

The contrast between SAP and third person is not the only distinction that can trigger alternations. Animacy and humanness ${ }^{11}$ are further factors that may condition changes in case marking, agreement, in word order and in the complexity of the verbal stem itself. Before proceeding to the morphosyntactic alternations in Section 3.2 and 3.3, some lexical alternations conditioned by the referential properties of the arguments are presented in Section 3.1. Section 3.4 finally introduces a serialization that is driven by the referential properties of $\mathrm{T}$.

\subsection{Lexical alternations}

The referential properties of arguments are naturally also part of the lexical semantics of the verbs. For instance, pipma (stem: pi ?) 'give', khuma (stem: khus) 'steal' and khupma (stem: khut) 'bring for others, deliver' cannot refer to events involving human T arguments, while khepma (stem: khet) 'carry off, take with oneself' is unrestricted in this respect. The verbs with restrictions on $\mathrm{T}$ have to undergo a serialization in order to express scenarios with human $\mathrm{T}$ arguments. As for the alternations of simple (non-derived) stems, this is best illustrated by the three different stems for 'send'. The first stem, haks hay, is used when non-human T arguments are transferred, while there are no restrictions on the nature of G. This verb belongs to the indirective frame (17).
ka $\quad n d a=b e$ kitab $1 \mathrm{SG}[\mathrm{NOM}] \quad 2 \mathrm{SG}=\mathrm{LOC}$ book$[\mathrm{NOM}]$ 'I send you a book.'

\footnotetext{
${ }^{11}$ The specific border between the conditions is hard to establish, as there are not sufficient data with non-human animate $\mathrm{G}$ arguments. Most examples involve only the human vs. inanimate contrast. Also, the border seems to vary from verb to verb, depending on how typical or plausible animate or human $\mathrm{G}$ arguments are for each verb. In the following, the term 'animate' stands for 'at least human, possibly also non-human'.
} 


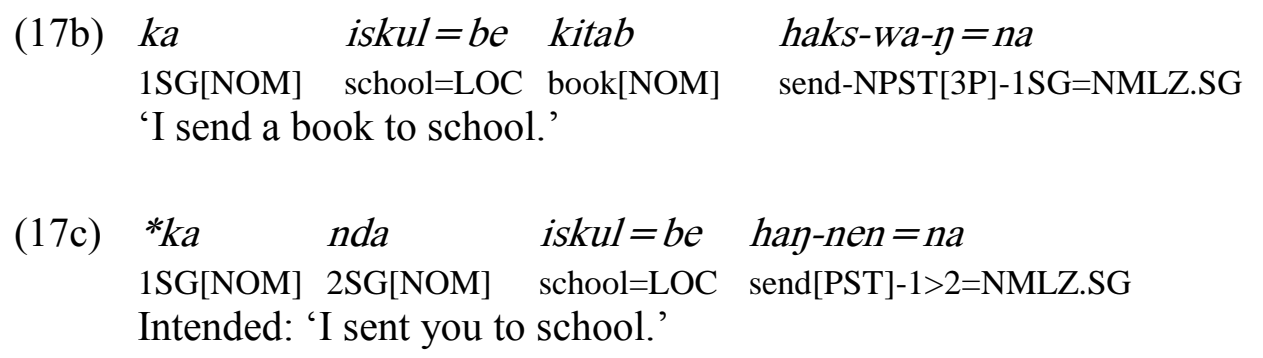

Etymologically related, but from the double object frame, is the stem hakt. This stem is also used to express the transfer of non-human themes (18), but the $\mathrm{G}$ argument must be human, as (18c) is unacceptable. This makes sense also from a historical point of view, as the stem augment $-t^{12}$ usually adds a benefactive argument to the verbal frame.
ka
$n d a$
$1 \mathrm{SG}[\mathrm{NOM}] \quad 2 \mathrm{SG}[\mathrm{NOM}]$
'I sent you a book.'
kitap hak-nen $=$ na
book[NOM] send[PST]-1>2=NMLZ.SG
a-pagyam
salen
hakt-wa- $\eta=n a$
1SG[NOM] 1SG.POSS-old.man[NOM] message[NOM] send-NPST[3P]-1SG=NMLZ.SG
'I send a message to my husband.'
*ka iskul
kitap
hakt-u- $\eta=n a$
1SG[NOM] school[NOM] book[NOM]
send-3P.PST-1SG=NMLZ.SG
Intended: 'I sent a book to the school.'

The third stem, paks, denotes the transfer of humans. It belongs to the indirective frame. The locative-marked $\mathrm{G}$ argument can have any reference. There is, however, no corresponding benefactive double object stem pakt, as one could assume in parallel to the stems haks and hakt.

$$
\begin{array}{llll}
u \eta=\eta a & u-c y a & n d a=b e & \text { paks- }- \text { =na } \\
\text { 3SG=ERG } & \text { 3SG.POSS-child[NOM] } & \text { 2SG=LOC } & \text { send[3A]-3P.PST=NMLZ.SG } \\
\text { 'He sent his child to you.' } & &
\end{array}
$$
$k a$
a-cya
bides $=$ be
paks-Wa- $\eta=n a$
1SG[NOM] 1SG.POSS-child[NOM] abroad=LOC send-NPST[3P]-1SG=NMLZ.SG
'I send my child (*a goat, *a present) abroad.'

\subsection{Alternations related to the animacy of arguments}

The verb hambipma 'distribute' from the double object frame shows case alternations conditioned by the animacy of G. The verb belongs to the double object frame and is a

\footnotetext{
${ }^{12}$ The augment is related to the Proto-Tibeto-Burman transitivizer $*_{\text {-t }}$ (Matisoff 2003:457). Reflexes of this transitivizer are found in stem correspondences such as ap 'come', apt 'bring' or yuks 'put', yukt 'put for someone' in Yakkha, and the augment is also productively attached to verbal roots in the benefactive derivation.
} 
benefactive derivation of hamma (stem: haps) 'divide, spread, distribute'. When the G argument is referentially high and the $\mathrm{T}$ argument is lower, i.e. in the expected type of scenario, both nonagent arguments are in the unmarked nominative, while the verb agrees with $\mathrm{G}$, exemplified by (20a). When the $G$ argument is inanimate, as in example (20b), a locative marker has to be attached to $\mathrm{G}$, but the verbal agreement remains with $\mathrm{G}^{13}{ }^{13}$ (20c) shows that the locative marker on $\mathrm{G}$ does not show up when it is human but third person; it only marks inanimate $\mathrm{G}$ arguments. The animacy of $\mathrm{G}$ is also reflected in the constituent order. Animate $\mathrm{G}$ arguments tend to precede the $\mathrm{T}$ argument, as in (20a) and (20c), while inanimate $\mathrm{G}$ arguments in the locative tend to follow the $\mathrm{T}$ argument.

(20a) ka nninda photo(-ci) ham-biP-me?-nen-in =ha 1SG[NOM] 2PL[NOM] photo(-NSG) divide-BEN-NPST-1>2-2PL=NMLZ.NSG 'I distribute the photos among you.'

(20b) sarkar= ya yay ten-ten $=$ be $\quad$-haps-u-bi-ci=ha government=ERG money[NOM] village-REDUP=LOC 3PL.A-divide-3P[PST]-BEN-3NSG.P=NMLZ.NSG 'The government distributed the money among the villages.'
(20c) $\mathrm{ka}$
picha-ci
yay
haps- $u-b i-\eta-c i-\eta=h a$
1SG[NOM] child-NSG[NOM] money[NOM] divide-3P[PST]-BEN-1SG-3NSG.P-1SG=NMLZ.NSG
'I distributed the money among the children.'

In contrast to the verb hambipma 'distribute' that only alternates in case marking, khupma 'bring for others, deliver' alternates between the double object frame and the indirective frame, thereby changing its patient agreement from $G$ to $T$. The condition for this alternation is again the animacy of $\mathrm{G}$. In example (21a) and (21b), the $\mathrm{G}$ argument has human reference, and the alignment follows the double object frame, while in example (21c), the $\mathrm{G}$ argument is a location, and the alignment is indirective. Here, too, the inanimate $\mathrm{G}$ argument follows the $\mathrm{T}$ argument, while the animate $\mathrm{G}$ argument precedes $\mathrm{T}$.
(21a) $k a$
SAr
kitab
khut-u-on $=$ na
1SG[NOM] teacher[NOM] book[NOM] deliver-3P-1SG.PST=NMLZ.SG

'I brought the teacher the book.'

$\begin{array}{llll}k a & n d a & \text { sandhisa } & \text { khui-nen=na } \\ \text { 1SG[NOM] } & \text { 2SG[NOM] } & \text { present[NOM] } & \text { deliver[PST]-1>2=NMLZ.SG } \\ \text { 'I brought you a present.' }\end{array}$

\footnotetext{
${ }^{13}$ Also the nominal nonsingular marker - $c i$ shows animacy effects. While it is obligatory with human referents, it is optional with other animate participants and with inanimates. Participants that are not marked for nonsingular may still trigger nonsingular agreement in the verb, as e.g. the T argument in (20a) triggers the nonsingular nominalizer. Also the nonsingular marking by reduplication in (20b) that conveys a distributional or iterative meaning is only found with inanimate participants. The optionality of the nonsingular marker is a general feature of Yakkha, not just restricted to three-argument verbs.
} 


$\begin{array}{llll}u \eta=\eta a & \text { kitab }(-c i) & i s k u l=b e & \text { khut }-u-c i=h a \\ \text { 3SG=ERG } & \text { book[NOM](-NSG) } & \text { school=LOC } & \text { deliver[3SG.A]-3P[PST]-3NSG.P=NMLZ.NSG } \\ \text { 'He brought the books to school.' }\end{array}$

In this subsection, the effects of the animacy of $\mathrm{G}$ were exemplified with hambipma 'distribute' and khupma 'bring'. Inanimate $\mathrm{G}$ arguments are likely to receive locative case marking, or they trigger an alternation from the double object frame to the indirective frame. Also the constituent order is sensitive to the animacy or humanness of the $G$ argument. As $G$ arguments are typically higher on the referential hierarchy than $\mathrm{T}$ arguments, these alternations are triggered by the pragmatically marked scenarios with referentially low $G$ arguments, i.e. those that have inanimate or non-human reference.

\subsection{Alternations between the indirective and the secundative frame}

Several verbs alternate between the indirective and the secundative frame, which is crosslinguistically not uncommon and also known as spray-load alternation. The verb ipma (stem: ipt) 'fill' belongs to this group. Either the G argument is in the locative and the $\mathrm{T}$ argument triggers agreement (indirective frame, (22a)), or the $\mathrm{T}$ argument is in the instrumental case and the $\mathrm{G}$ argument triggers the agreement in the verb (secundative frame, (22b)). As this verb is hardly imaginable with a human/animate $G$ argument, animacy cannot be a factor for this verb, so that the alternation is most probably related to the question which argument is central in a given discourse. ${ }^{14}$

$$
\begin{array}{lll}
\text { gagri=be } & \text { mancwa } & \text { ipt- } u \\
\text { pot=LOC } & \text { water[NOM] } & \text { fill-3P[IMP] }
\end{array}
$$

'Fill the water into the pot.'

$$
\begin{aligned}
& \text { ka makai=na dalo ipt-wa- } \eta=n a \\
& 1 \mathrm{SG}[\mathrm{NOM}] \quad \text { corn=INS sack[NOM] fill-NPST[3P]-1SG=NMLZ.SG }
\end{aligned}
$$

'I filled the sack with corn.'

If the meaning of the verb allows some flexibility of the referential properties of the arguments, the alternation can also be conditioned by the animacy of the $\mathrm{G}$ and the $\mathrm{T}$ argument. For the verb lepma (stem: lept) 'throw', for instance, the semantically unmarked scenario involves an animate $\mathrm{G}$ and an inanimate $\mathrm{T}$ argument. In this expected scenario, both frames are possible, such as in (23). In (23a) the $\mathrm{G}$ argument kucumaci 'dogs' triggers the object agreement in the verb, and the $\mathrm{T}$ argument is marked with an instrumental case. In (23b), the verb agrees with the $\mathrm{T}$ argument lugkhwak 'stone', while the G argument is in the locative case. The difference between them apparently has to do with the topicality of the arguments. In (23a), the dogs are central to the discourse, in (23b) it is the stone.

\footnotetext{
${ }^{14}$ As no detailed study of the information structure was conducted yet, and as these examples are elicited, I do not want to make strong commitments about topic and focus. In spontaneous speech, topical participants are rarely overt, and even new participants are commonly introduced just by the verbal agreement, without being overtly mentioned by an NP (cf. also Bickel (2003) on referential density in Belhare, which is closely related to Yakkha).
} 

ka kucuma-ci lunkhwak= na
lept-u- $\eta-c i-\eta=h a$.
$1 \mathrm{SG}[\mathrm{NOM}] \operatorname{dog}[\mathrm{NOM}]-\mathrm{NSG}$ stone=INS
throw-3P[PST]-1SG-3NSG.P-1SG=NMLZ.NSG

'I threw a stone at the dogs.'
$\mathrm{ka}$
lupkhwak kucuma-ci=be
lept-u- $\eta=n a$.
1SG[NOM] stone[NOM] dog-NSG=LOC
throw-3P[PST]-1SG=NMLZ.SG

'I threw the stone at the dogs.'

The alternation towards the secundative frame is not possible when the $\mathrm{G}$ argument is inanimate (24a). The secundative frame (in alternating verbs, not in all verbs of the secundative frame) requires an animate $\mathrm{G}$ argument that has the potential to be affected by the event. Furthermore, events with an animate $\mathrm{T}$ argument cannot be expressed at all by the verb lepma (24c-d). Instead, a serial verb construction that adds a second verbal stem to lepma has to be used, which is discussed in detail in Section 3.4.

$$
\begin{aligned}
& \text { *ka mancwa lunkhwak= pa lept-u- } \eta=h a \\
& 1 \mathrm{SG}[\mathrm{NOM}] \text { water[NOM] stone=INS throw-3P[PST]-1SG=NMLZ.NSG }
\end{aligned}
$$

(24b) $k a$

\begin{tabular}{|c|c|c|c|c|}
\hline$(24 c)$ & $\begin{array}{l}{ }^{*} k a \\
1 \mathrm{SG}[\mathrm{NOM}]\end{array}$ & $\begin{array}{l}n d a=\eta \mathrm{a} \\
2 \mathrm{SG}=\mathrm{INS}\end{array}$ & $\begin{array}{l}\operatorname{majcwa} \\
\text { water[NOM] }\end{array}$ & $\begin{array}{l}\text { lept }-u-\eta=h a \\
\text { throw-3P[PST]-1SG=NMLZ.NSG }\end{array}$ \\
\hline$(24 d)$ & $\begin{array}{l}{ }^{*} k a \\
1 \mathrm{SG}[\mathrm{NOM}]\end{array}$ & $\begin{array}{l}n d a \\
2 \mathrm{SG}[\mathrm{NOM}]\end{array}$ & $\begin{array}{l}\text { mancwa }=b e \\
\text { water=LOC }\end{array}$ & $\begin{array}{l}\text { lep-nen }=n a \\
\text { throw[PST]-1>2=NMLZ.SG }\end{array}$ \\
\hline
\end{tabular}

$\begin{array}{llll}k a & \text { lunkhwak } & \text { mancwa=be } & \text { lept- } u-\eta=n a \\ 1 \mathrm{SG}[\mathrm{NOM}] & \text { stone[NOM] } & \text { water=LOC } & \text { throw-3P[PST]-1SG=NMLZ.SG }\end{array}$

'I threw a stone into the water.'

Another verb showing this alternation and the mentioned restrictions is akma (stem: akt) 'kick'. Example (25a) and (25b) show that the indirective frame is possible with both inanimate and animate $\mathrm{G}$ arguments.

$$
\begin{array}{llll}
k a & g o l & j y a l=b e & a k t-u-\eta=n a \\
1 \mathrm{SG}[\mathrm{NOM}] & \text { ball[NOM] } & \text { window=LOC } & \text { kick-3P[PST]-1SG=NMLZ.SG }
\end{array}
$$

'I kicked the ball into the window.'

$$
\begin{array}{llll}
k a & u p c i=b e & g o l & a k t-u-\eta=n a \\
1 \mathrm{SG}[\mathrm{NOM}] & \text { 3NSG=LOC } & \text { ball[NOM] } & \text { kick-3P[PST]-1SG=NMLZ.SG }
\end{array}
$$

'I kicked the ball at/to them.'

As with lepma 'throw', the $\mathrm{G}$ needs to be an animate participant in order to enable the secundative frame, as in (26a). Examples like (26b) are ungrammatical, as the G argument is inanimate and cannot be affected by the event. 
(26a) ka nda gol=na ak-nen?

$1 \mathrm{SG}[\mathrm{NOM}] \quad 2 \mathrm{SG}[\mathrm{NOM}]$ ball=INS kick-1>2[SBJV]

'Shall I kick the ball at you?'
*ka jyal gol=na akt-u-n?
$1 \mathrm{SG}[\mathrm{NOM}]$ window[NOM] ball=INS kick-3P-1SG[SBJV]
Intended: 'Shall I kick the ball to the window?'

Also lupma (stem: lupt) 'scatter, disperse, strew' can undergo this alternation. In example (27a), the $\mathrm{G}$ argument is non-overt, but has human reference, which is obvious from the real world context of a burial. In (27b), the G argument is a location and, hence, inanimate.

(27a) Kham = pa lupt-u-ga=i

soil=INS scatter-3P[IMP]-2=PTCL

'Cover him with sand.'

$$
\text { yenda }=\text { be } \quad \text { khawa } \quad \text { lupt-u-g }=h a=i ?
$$

millet.mash $=$ LOC yeast[NOM] scatter-3P[PST]-2=NMLZ.NSG=Q

'Did you put yeast into the millet mash?' (beer brewing procedure)

To conclude this section, the Yakkha alternations show that animate arguments (both $\mathrm{T}$ and $\mathrm{G}$ ) tend to be in the unmarked nominative, while instrumental case (for theme) and locative case (for goal) are preferred for inanimate arguments. Concerning $\mathrm{G}$ arguments, this correlation confirms what is stated in Universal 1 in Haspelmath (2007:84). But for animate T arguments, one should expect the opposite, as they are pragmatically unexpected and thus more likely to require special marking (cf. Universal 2 in Haspelmath 2007:87). In none of the frames of Yakkha threeargument verbs, a referentially high $\mathrm{T}$ argument receives special case marking. What one finds, however, is an increase in the morphological complexity of the verb when the $\mathrm{T}$ argument has unexpected high referential value, in line with Universal 3 stated in Haspelmath (2007:90; cf. Section 3.4 below).

Regarding agreement, in those verbs that alternate between the secundative and the indirective frame, the human/animate argument (i.e. the argument in the nominative case) is likely to trigger the object agreement in the verb. Thus, the spray-load alternation can be regarded as hierarchical alignment as well, with human/animate participants outranking inanimate participants, regardless of their syntactic role. This morphosyntactic behaviour is not surprising, as verbal agreement favours human referents crosslinguistically (Siewierska 2003:356).

\subsection{A serialization pattern conditioned by atypical $T$ arguments}

Verb serialization ${ }^{15}$ can be characterized as the modification or 'fine tuning' of the semantic orientation of a verb by means of another verb (Masica 2001:250). This process is a common

\footnotetext{
${ }^{15}$ In the tradition of South Asian language description also known as ('explicator') compound verbs, and possibly also comparable to what is known e.g. as 'resultative' verbs in descriptions of South East Asian languages (Masica
} 
feature of many languages of South Asia, crosscutting genetic boundaries. It can not only be found in Kiranti languages (Bickel 1996, Ebert 1997, Doornenbal 2009), but also in other Tibeto-Burman languages, among them Modern Tibetan (DeLancey 1991), Newari (Kansakar 2005), Lahu (Matisoff 1969), in Indo-Aryan languages such as Hindi/Urdu, Gujarati and Nepali (Pokharel 1999, Nespital 1997), but also in Dravidian and in Munda languages.

In Yakkha, there are more than twenty grammaticalized ${ }^{16}$ verb stems (henceforth 'V2') that are responsible for specifying the verbal semantics, with respect to categories as diverse as aspect/Aktionsart, modality, phasality and the spatial orientation of an event. They are also employed in transitivity operations, such as causatives, applicatives, reflexives and reciprocals. Crucially, both verbs (lexical verb and V2) contribute to the semantics and sometimes also to the argument structure of the resulting complex predicate (Butt 1995:2). This is exemplified here briefly with a benefactive (valency-increasing) and a reflexive (valency-decreasing) serialization. The lexical meaning of the benefactive pi? ( bhy) in (28a) is, unsurprisingly, 'give'; the V2 $c a$ marking the reflexive in (28b) has the lexical meaning 'eat'. These serial verbs are inflected as follows: the lexical verb hosts the prefix (if there is one) and sometimes the first suffix, while the V2 hosts the full suffix string. ${ }^{17}$

$\begin{array}{llll}\text { (28a) } & k a & c a b h i & y o k-t-a-b h y-a-\eta \\ & 1 \mathrm{SG}[\mathrm{NOM}] & \text { key[NOM] } & \text { search-AUG-IMP-V2.BEN-IMP-1SG }\end{array}$

'Search the key for me.' (three arguments, transitive inflection)

(28b) $\mathrm{ka} \quad$ (aphai) mon-ca-me- $\eta=n a$

$1 \mathrm{SG}[\mathrm{NOM}]$ (self) beat-V2.REFL-NPST-1SG=NMLZ.SG

'I beat myself.' (one argument, intransitive inflection)

The functions of the serial verbs in Yakkha are manifold, and not restricted to three-participant events; but one function is the introduction of a referentially high $\mathrm{T}$ argument. There is some variation among speakers and also for the different verbs as to what the condition for the serialization is. Some speakers consider human third person $\mathrm{T}$ arguments fine without the serialization, but the general tendency to employ the serialization with referentially high $\mathrm{T}$ arguments is obvious. As mentioned in the preceding sections, many three-argument verbs cannot express human or SAP T arguments without prior serialization. This serialization may also change the argument structure of the resulting complex predicate. The verb pipma 'give', for instance, requires the V2 haks $\sim$ hay $\sim$ hhay 'send' to indicate a human T. ${ }^{18}$ Compare (29) (with inanimate T) and (30) (with human, SAP T):

\footnotetext{
2001:250).

${ }^{16}$ 'Grammaticalization' is understood here as a process by which a formerly purely lexical item acquires a productive grammatical function in morphosyntax, accompanied by a loss of the original lexical semantics, e.g. the verb 'give' becoming a benefactive marker or the verb 'go' becoming a marker for the telic orientation of an event. Occasionally, lexical serialization can also be found, i.e. when the V2 retains its lexical meaning, for instance $y o n-$ $c a(-m a)$ 'fry and eat'.

${ }^{17}$ The reasons why some serial verbs allow inflectional material between the two verbal stems and others do not it are not fully understood yet.

${ }^{18}$ One could suspect that the lexical semantics of the $\mathrm{V} 2$ involve a human $\mathrm{T}$ argument, to have a functional motivation for this grammaticalization. But as laid out in Section 3.1, the stem haks is characterized precisely by the opposite semantics, namely by non-human $\mathrm{T}$ arguments. The stem that means 'send humans' is paks $\sim$ pay. The serial verb here can however also be taken literally, as giving away a daughter in marriage also means to send her to
} 
(29a) ka nda eko coklet pir-nen $=$ na

$1 \mathrm{SG}[\mathrm{NOM}] 2 \mathrm{SG}[\mathrm{NOM}]$ one sweet[NOM] give[PST]-1>2=NMLZ.SG

'I gave you a sweet.'

(29b) $\mathrm{ka}$

$$
\text { photo(-ci) pi-a- } \eta-g=h a
$$

1SG[NOM] photo[NOM](-NSG) give-PST-1SG-2=NMLZ.NSG

'(You) gave me the photos.'

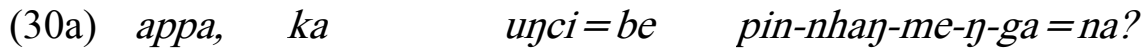

father 1SG[NOM] 3NSG=LOC give-V2-NPST-1SG-2=NMLZ.NSG

'Father, will you give me to them (in marriage)?'

(30b) $\mathrm{ka}$ nda unci=be pin-nhay-me?-nen=na

1SG[NOM] 2SG[NOM] 3NSG=LOC give-V2-NPST-1>2=NMLZ.SG

'I (will) give you to them (in marriage).'

The arguments in (29) have the expected referential properties (SAP G and inanimate T), and the predicate belongs to the double object frame. But in (30) an SAP T argument is transferred to a third person recipient, so that the serialization has to apply. The V2 has to be attached to the lexical verb (triggering regressive assimilation to a nasal in the stem /pi?/ to [pin]), and the resulting complex predicate belongs to the indirective frame, with the T triggering agreement and $\mathrm{G}$ in the locative case.

One has to distinguish two conditions at work in this alternation. The serialization and the locative on $\mathrm{G}$ are conditioned by the human $\mathrm{T}$ argument, but the alternation towards agreement with $\mathrm{T}$ only occurs in the scenario $\mathrm{T}-\mathrm{SAP} \rightarrow \mathrm{G}-3$, in the same vein as in the alternations of camepma 'feed' and sopmepma 'show' in Section 2.1. In (31), showing examples with both $\mathrm{T}$ and $\mathrm{G}$ being SAP, the serialization and the locative on $\mathrm{G}$ apply, but the verb still agrees with $\mathrm{G}$. Thus, while the serialization and the locative case marking depend on the referential properties of one argument, the agreement alternation is scenario-dependent. In scenarios such as in (30) above, the resulting predicate ends up belonging to neither of the main frames, but with secundative agreement and indirective case marking (as the $\mathrm{T}$ is in the nominative case, like the monotransitive $\mathrm{P}$ ).

$$
\begin{array}{llll}
m-b a=n a & n d a & k a=b e & \text { pin- } n h a \eta-m e-n=n a=b u=i
\end{array}
$$

$$
\begin{array}{llll}
\text { a-ppa }=\eta \mathrm{k} a & \mathrm{ka} & n d a=b e & \text { pin-nhan-me-ga=na } \\
\text { 1SG.POSS-father=ERG } & \text { 1SG[NOM] } & \text { 2SG=LOC } & \text { give-V2-NPST[3SG.A]-2=NMLZ.SG } \\
\text { 'My father will give me to you (in marriage).' } &
\end{array}
$$

the groom's household, since the Yakkha society is patrilocal. This still does not explain why it was not the stem paks $\sim$ pay that made it into the marker for human $\mathrm{T}$ arguments here (and with other verbs). 
Not only the V2 haks hay nhay 'send' is found in this function; other stems employed as V2 in three-argument verbs are end 'insert', da? ra? 'bring', na? 'leave' and het 'cut, stop, obstruct', their choice depending partly on the semantics of the lexical verb and partly on the desired semantic outcome. Example (32) shows a serialization with na? 'leave' as V2 (lexical meaning possibly 'leave'). Compare the simple lexical stem et 'put/apply (for s.o.)' in (32a) with the serial verb (32b), and how the frame changes from double object to indirective, so that the verb agrees with $\mathrm{T}$ instead of $\mathrm{G}$. Other examples of compounds with na? 'leave' are ti?nama 'bring, deliver (somewhere)' and phe Inama 'drop at' (32c), and also na Inama 'leave at'.

$\begin{array}{llll}n d a & k a & c u w a & \text { et-a- } \eta-g=h a \\ \text { 2SG[NOM] } & \text { 1SG[NOM] } & \text { beer[NOM] } & \text { put-PST-1SG-2SG=NMLZ.NSG }\end{array}$

'You put beer (there) for me.'

ka nda bo:din $=$ be $\quad$ et-na-nen $=n a$

1SG[NOM] 2SG[NOM] boarding.school=LOC put-V2-1>2[PST]=NMLZ.SG

'I enrolled you at boarding school (and went home without you).'

\footnotetext{
ka pashupatināth $=$ pe phe?-na-ma- $\eta=n a$

1SG[NOM] a.place=LOC drop-V2-PRF[3SG.A;PST]-1SG=NMLZ.SG

'He has dropped me at Pashupatinath.'
}

A verb that does not change its frame, but still requires a V2 is khus 'steal'. As this verb belongs to the indirective frame, the attachment of a V2 het 'stop, obstruct, cut' does not change the case and agreement properties of the verb, but the serialization is still necessary in order to express the human $\mathrm{T}$ in (33b), as opposed to the inanimate $\mathrm{T}$ in (33a).

$$
\begin{array}{lll}
\text { pushl=bhay } & \text { yay } & \text { khus-uks-u=ha} \\
\text { shop=ABL } & \text { money[NOM] } & \text { steal-PRF-3P[PST]=NMLZ.NSG }
\end{array}
$$

'(He) has stolen money from the shop.'

\begin{tabular}{|c|c|c|c|}
\hline ka & ijay & $a-p a \eta=b h a \eta$ & khus-het-a- $\eta-g a=n a ?$ \\
\hline
\end{tabular}

In verbs that alternate between the PO frame and the DO frame (cf. also Section 3.3), the PO frame is not available for scenarios with human $\mathrm{T}$ arguments and locational $\mathrm{G}$ arguments, and a serial structure with the stem haks nhay 'send' has to be used ((34a) and (34c), also triggering the assimilation of the stem-final stops to nasals). The underived verb form can only be understood as having the second person as $\mathrm{G}$ argument, following the PO frame $((34 \mathrm{~b})$ and (34d)).

(34a) lamdhay = be lem-nhay-nen?
field=LOC throw-V2-1>2[SBJV]
'Shall I throw you (out) into the field?'


(34b) lep-nen?

throw-1>2[SBJV]

'Shall I throw (it) at/to you?'

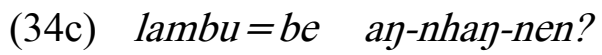

road=LOC kick-V2-1>2[SBJV]

'Shall I kick you (out) on the road?'

(34d) $(l a \eta=\eta a) \quad a k-n e n ?$

(foot=INS) kick-1>2[SBJV]

'Shall I kick you?'

Example (35) provides evidence for the serialization applying also to scenarios with third person human $\mathrm{T}$ arguments, not only with SAP arguments.

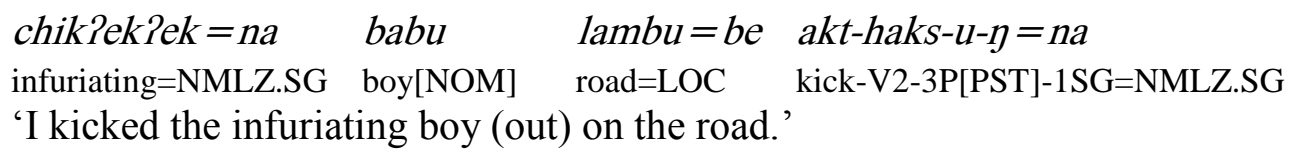

As there are several V2 with different semantics, it is not their exclusive function to indicate high $\mathrm{T}$ arguments in three-argument verbs. They can also be found with monotransitive verbs (36), and also with inanimate arguments (36a). The semantics of haks nhay 'send', for instance, specifies the event as involving some movement away from the deictic centre.
(36a) kasinra lept-haks-u- $\eta=h a$
$\operatorname{dir}[\mathrm{NOM}] \quad$ throw-V2-3P[PST]-1SG=NMLZ.NSG
'I threw the dirt away.'

(36b) nhay ikt-haks-a-ma-c-u-ci

and.then chase-V2-PST-PRF-DU-3P-3NSG.P

'And then they (dual) chased them away.' [22_kth_05.009]

Although the serialization is found in such scenarios as well, the crucial point is that certain scenarios cannot be expressed without using a V2. Referentially high $\mathrm{T}$ arguments require the semantic specification of an event by a second verb stem. They simply cannot be left unspecified, and simple verbs like 'bring', 'give', 'steal' are inappropriate with human T arguments. There can be different ways to manipulate the semantics of the lexical verb, by choosing different V2. Another example of the verb khuma 'steal' shall illustrate this. If the V2 het 'stop, obstruct, cut' is added, it means that the person was stolen and led or carried away (37a), but if the V2 haks nhay 'send' is added instead, the semantics change towards 'rescue'. To conclude, the higher complexity and greater semantic specification of an event via serialization is necessary in, but not restricted to events with $\mathrm{T}$ (and P) arguments that are exceptionally high on the referential hierarchy. 
(37a) $k a$

ijal 1SG[NOM] why 'Why did you steal me from my home?' khus-het-a- $\eta$-ga $=$ na

steal-V2-PST-1SG-2=NMLZ.SG

kiba = bhan khus-haks-a- $\eta-g a=n a$

tiger=ABL steal-V2-PST-1SG-2=NMLZ.SG

'You saved me from the tiger.'

\section{Summary and Conclusions}

This survey of referential effects in three-participant constructions in Yakkha showed that several conditions can be defined and several morphosyntactic effects can be found for each verb. Conditions that involve the properties of only one argument and those involving a whole scenario type (i.e. argument and co-argument) need to be distinguished. The referential distinctions crucial for Yakkha are those between SAP and third person and those between animates (humans) and inanimates. ${ }^{19}$ Table 7 summarizes all conditions and alternations found.

Scenarios of the $\mathrm{T}[\mathrm{SAP}] \rightarrow \mathrm{G}[3]$ type may have three effects: (a) hierarchical alignment of agreement, i.e. the alternation of agreement and (b) case alternations (cf. sopmepma 'show' and camepma 'feed'), and (c) the restriction of alternation possibilities (cf. nakma 'ask'). One lesson from Yakkha three-participant constructions is that hierarchical alignment of agreement may apply in the expression of three-participant events even if this mechanism is irrelevant in the expression of monotransitive events. The distinction along the person ranking [SAP > 3] is an important organizing principle in the grammar of Yakkha. Further evidence, beyond threeargument verbs, for the privileged status of SAP arguments over third person arguments is provided by the ergative/nominative case alignment split (nominative with SAP pronouns), by underspecified SAP agreement morphemes such as $-m(1 / 2 \mathrm{pl} . \mathrm{A})$ and $-i(1 / 2 \mathrm{pl}$.S/P), as well as by a peculiar alignment pattern in one complement construction.

\begin{tabular}{|c|c|c|}
\hline condition & effect & verbs \\
\hline \multirow[t]{3}{*}{$\mathbf{T}[\mathrm{SAP}] \rightarrow \mathbf{G}[3]$} & $\operatorname{agr}[\mathrm{T}], \mathrm{G}-\mathrm{LOC}$ & sopmepma 'show' (double object) \\
\hline & $\operatorname{agr}[\mathrm{T}]$ & camepma 'feed' (double object) \\
\hline & restricted to indirective frame & nakma 'ask' (double object $\sim$ indirective) \\
\hline \multirow[t]{4}{*}{ G[inan] } & \multirow[t]{2}{*}{ restricted to indirective frame } & lepma 'throw' (secundative $\sim$ indirective) \\
\hline & & akma 'kick' (secundative $\sim$ indirective) \\
\hline & G-LOC & hambipma 'distribute' (double object) \\
\hline & indirective frame & $\begin{array}{l}\text { khupma 'bring, deliver' } \\
\text { (double object } ~ \text { indirective) }\end{array}$ \\
\hline \multirow[t]{2}{*}{ T[SAP] } & \multirow[t]{2}{*}{ G-LOC } & sopmepma 'show' (double object) \\
\hline & & pinnhayma 'give (humans)' (indirective) \\
\hline T[human] & $\begin{array}{l}\text { serialization, leading to } \\
\text { indirective frame }\end{array}$ & (many) \\
\hline
\end{tabular}

Table 7: Summary of hierarchy effects in three-argument verbs

\footnotetext{
${ }^{19}$ As all alternations presented depend on the distinction between only two referential values, I find it misleading to call these distinctions 'hierarchies'.
} 
As for the alternations in case marking (as far as not mentioned above already), I have shown that the conditions for special case marking may lie in the referential properties of the argument itself or in those of the co-argument. Locative case marking, for instance, can be conditioned by the (low) referential properties of $\mathrm{G}$ itself (Section 3.2), or by the (high) referential properties of $\mathrm{T}$ (Sections 2.1, 3.3 and 3.4). In Section 3.3 I have demonstrated that also the instrumental marking on $\mathrm{T}$ is dependent on the properties of its co-argument, as only animate, $\mathrm{G}$ arguments permit the instrumental case marking on $\mathrm{T}$ (and thus the secundative frame) in verbs that follow the spray-load alternation. An unexpected finding for case is that there is no special marking for referentially high $\mathrm{T}$ arguments, as would be expected from the predictions made in Haspelmath (2007:87). Instead, a general tendency to prefer animate arguments (either $T$ and $G$ ) in the nominative case (and triggering agreement) could be encountered. Moreover, relating to the question of how to define three-argument verbs and where to draw the border between arguments and adjuncts, the case alternations, e.g. G-NOM to G-LOC clearly show that oblique-marked participants cannot be discarded as adjuncts per se; this marking may just reflect the referential properties of the arguments.

The three-argument verbs also showed a strong tendency to occur in serial constructions, constructed by the attachment of one of various V2 to the lexical stem, when the T argument was human (or SAP). As the main function of these V2 is a semantic specification of an event, I conclude that the simple stems are often underspecified and that referentially high $\mathrm{T}$ (and $\mathrm{P}$ ) arguments require the specification of the event by a V2. The higher complexity of the verb, to some extent comparable to inverse marking in monotransitive verbs, is exactly what is predicted by Haspelmath (2007:90) for scenarios with untypically high T arguments.

I have shown that the referential properties of the arguments can play a vital role in altering case and agreement in three-argument verbs, given that the verbs allow a certain flexibility of the referential properties of their arguments. A final remark is in order: as the majority of the examples provided here is elicited, more insights could be gained from a bigger corpus of spontaneous speech, which is currently being processed.

\section{Abbreviations}

(Glosses adhering to the Leipzig Glossing Rules)

1,2,3 - person, 1>2 first person acting on second (portmanteau morpheme), A - most agent-like argument of transitive clause, ABL - ablative case, ADD - additive focus, AUG - stem augment, BEN - benefactive, CAUS - causative, COM - comitative case, COMPL completive, DU - dual, ERG - ergative case, EXCL - exclusive, G - most goal-like argument of transitive clause, GEN - genitive case, IMP - imperative, INS - instrumental, LOC - locative case, NEG - negation, NMLZ - nominalizer, NOM - nominative case, NPST - nonpast, NSG nonsingular, OPT - optative, P - most patient-like argument of transitive clause, PL - plural, POSS - possessive, PRF - perfect, PST - past, Q - question particle, REDUP - reduplication, REFL - reflexive, REP - reportative, $S$ - sole argument of intransitive clause, SBJV subjunctive, SG - singular, T - most theme-like argument of transitive clause, TOP - topic, V2 second stem in serial verb 


\section{References}

Bickel, Balthasar. 1996. Aspect, mood, and time in Belhare: Studies in the semantics-pragmatics interface of a Himalayan language. Vol. 15 of ASAS. Zürich: Seminar für Allgemeine Sprachwissenschaft.

-----. 1999. Nominalization and focus constructions in some Kiranti languages. Topics in Nepalese linguistics, ed. by Yogendra P. Yadava and Warren W. Glover. 271 - 296. Kathmandu: Royal Nepal Academy.

-----. 2003a. Belhare. The Sino-Tibetan languages, ed. by Graham Thurgood and Randy J. LaPolla. 546 - 70. London: Routledge.

-----. 2003b. Referential density in discourse and syntactic typology. Language 79.708 - 736.

-----. 2010. Grammatical relations typology. The Oxford Handbook of Language Typology, ed. by Jae Jung Song, 399 - 444. Oxford: Oxford University Press.

Bickel, Balthasar, Manoj Rai, Netra Paudyal, Goma Banjade, Toya Nath Bhatta, Martin Gaenszle, Elena Lieven, Iccha Purna Rai, Novel K. Rai and Sabine Stoll. 2010. The syntax of three-argument verbs in Chintang and Belhare (Southeastern Kiranti). Studies in ditransitive constructions, ed. by Andrej Malchukov, Martin Haspelmath and Bernard Comrie, 285-307. Berlin: Mouton de Gruyter.

Butt, Miriam. 1995. The structure of complex predicates in Urdu. Stanford: CSLI Publications.

Comrie, Bernard. 1989. Language universals and linguistic typology ( $2^{\text {nd }}$ edition). Chicago: University of Chicago Press.

DeLancey, Scott. 1991. The origin of verb serialization in Modern Tibetan. Studies in Language $15.1-23$.

-----. 2011. Finite Structures from Clausal Nominalization in Tibeto-Burman. Nominalization in Asian Languages: Diachronic and Typological Perspectives, ed. By Foong Ha Yap, Karen Grunow-Hårsta and Janick Wrona. Amsterdam: John Benjamins.

Doornenbal, Marius A. 2009. A grammar of Bantawa: Grammar, paradigm tables, glossary and texts of a Rai language of Eastern Nepal. Utrecht: LOT Publications.

Dowty, David R. 1991. Thematic proto-roles and argument selection. Language 67. 547 - 619.

van Driem, George. 1993. A grammar of Dumi. Berlin: Mouton de Gruyter.

Dryer, Matthew. 1986. Primary objects, secondary objects, and antidative. Language 62, 808 845.

Ebert, Karen. 1997. Camling (Chamling). LINCOM, München.

Givón, Talmy. 1976. Topic, pronoun, and grammatical agreement. Subject and topic, ed. By Charles N. Li, 149 - 188. New York: Academic Press.

Haspelmath, Martin. 2004. Explaining the Ditransitive Person-Role Constraint: A usage-based approach. Constructions (free online journal, University of Düsseldorf) 2, 49.

-----. 2005. Argument marking in ditransitive alignment types. Linguistic Discovery 3.1 - 21.

-----. 2007. Ditransitive alignment splits and inverse alignment. Functions of Language 14/1. 79102.

Kansākar, Tej Ratna. 2005. Classical Newar verbal morphology and grammaticalization in Classical and modern Newar. Himalayan Linguistics 3. 1-21.

LaPolla, Randy. 2007. Hierarchical Person Marking in the Rawang Language. Paper presented at the 40th International Conference on Sino-Tibetan Languages and Linguistics. Harbin, China.

Malchukov, Andrej L., Martin Haspelmath and Bernard Comrie. 2010. Ditransitive 
constructions: a typological overview. Studies in Ditransitive Constructions, ed. by Andrej L. Malchukov, Martin Haspelmath and Bernard Comrie, 1-36. Berlin: Mouton de Gruyter.

Margetts, Anna and Peter K. Austin. 2007. Three-participant events in the languages of the world: towards a crosslinguistic typology. Linguistics 45.393-451.

Masica, Colin. 2001. The definition and significance of linguistic areas: methods, pitfalls, and possibilities (with special reference to the validity of South Asia as a linguistic area). Tokyo Symposium on South Asian languages: contact, convergence, and typology [= The Yearbook of South Asian Languages and Linguistics 2001], ed. by Peri Bhaskararao and Karamuri V. Subbarao, 205-267. New Delhi: Sage Publications.

Matisoff, James A. 1969. Verb concatenation in Lahu: The syntax and semantics of 'simple' juxtaposition in Lahu. Acta Linguistica Hafniensia 12.69 - 120.

-----. 2003. Handbook of Proto-Tibeto-Burman: system and philosophy of Sino-Tibetan reconstruction. Berkeley: University of California Press.

Michailovsky, Boyd. 2003. Hayu. The Sino-Tibetan languages, ed. by G. Thurgood and R. LaPolla. 518 - 532. London: Routledge.

Miller, Amy. 2001. A grammar of Jamul Tiipay. Berlin: Mouton de Gruyter.

Nagano, Yasuhiko. 1984. A historical study of the rGyarong verb system. Tokyo: Seishido.

Nespital, Helmut. 1997. Hindi kriya-kosa: containing all simple and compound verbs, their lexical equivalents in English and illustrations of their usage. Allahabad: Lokbharati Prakasan.

Nichols, Johanna. 1992. Language diversity in space and time. Chicago: University of Chicago Press.

Pokharel, Madhav P. 1999. Compound verbs in Nepali. Topics in Nepalese Linguistics, ed. by Yogendra P. Yadava and Warren W. Glover, 185 - 208. Kathmandu: Royal Nepal Academy.

Siewierska, Anna. 2003. Person agreement and the determination of alignment. Transactions of the Philological Society 101.339 - 370.

Silverstein, Michael. 1976. Hierarchy of features and ergativity. Grammatical Categories in Australian Languages, ed. by Robert Dixon, 112-171. New Jersey: Humanities Press.

Toba, Sueyoshi, Ingrid Toba and Novel Kishore Rai. 2005. Diversity and Endangerment of Languages in Nepal. UNESCO Kathmandu Series of Monographs and Working Papers: No 7. Kathmandu: United Nations Educational, Scientific and Cultural Organization.

Witzlack-Makarevich, Alena. 2010. Typological variation in grammatical relations. PhD thesis, University of Leipzig.

Zúñiga, Fernando. 2007. From the typology of inversion to the typology of alignment. New Challenges in Typology: Broadening the Horizons and Redefining the Foundations, ed. by Matti Miestamo and Bernhard Wälchli, 199 - 221. Berlin: Mouton de Gruyter.

Author's Contact Information:

Diana Schackow

Max Planck Institute for Evolutionary Anthropology

Department of Linguistics

Deutscher Platz 6

04103 Leipzig

schackow@eva.mpg.de 